\title{
Mental Attribution in Interaction: How the Second Person Perspective Dissolves the Problem of Other Minds*
}

\author{
Atribución mental en la interacción: \\ De qué modo la perspectiva de segunda persona modifica el \\ problema del conocimiento de las otras mentes
}

ANTONI GOMILA** \& DIANA PÉREZ***

\begin{abstract}
In this paper, we will address the question of the impact of the second person perspective of psychological attribution on the traditional problem of knowing other minds. With that purpose in mind, we will introduce the notion of a second-personal perspective of mental attribution within the context of the classical problem of other minds, and discuss the epistemic and ontological implications that follow once the second person perspective is honored. In particular, we will examine how its recognition transforms the traditional problem of other minds, both in its epistemological, ontological and semantical dimensions, and offers a way to go beyond the objective/subjective dichotomy
\end{abstract}

\begin{abstract}
Resumen: En este trabajo enfrentaremos la cuestión del impacto de la perspectiva de segunda persona de la atribución mental en el problema tradicional del conocimiento de las otras mentes. Con este propósito en mente, introduciremos la noción de una perspectiva de segunda persona de la atribución mental en el contexto del problema clásico del conocimiento de las otras mentes, y discutiremios las implicaciones epistémicas y ontológicas que se siguen cuando se adopta la perspectiva de segunda persona. En particular, examinaremos cómo este reconocimiento transforma el tradicional problema de las otras mentes tanto en la dimensión epistémica como en las dimensiones ontológica y semántica, ofreciendo una manera de ir más allá de
\end{abstract}

Recibido: 28/05/2018. Aceptado: 21/10/2018.

* Este trabajo se ha beneficiado del apoyo de los proyectos FFI2013-44007-P y FFI2017-86351, del Goberno español para AG, y los proyectos argentinos UBACyT 20020170100215BA y PIP/CONICET 11220170100517CO para DP.

** Catedrático del Departamento de Psicología, Universitat de les Illes Balears; Investigador de evocog, unidad asociada al IFISC (CSIC-UIB). Contacto: Toni.gomila@uib.cat Líneas de investigación: segunda persona; psicología moral. Publicaciones recientes: Gomila, A.; Christensen, J.F. (2018) On the moral import of the arts: the case of music. Progress in Brain Research, 237: 471-484. Pérez Manrique, A.; Gomila, A. (2017) The comparative study of empathy: sympathetic concern and empathic perspective-taking in non-human animals. Biological Reviews 93(1): 248-269. doi: 10.1111/brv.12342.

*** Profesora Asociada, Departamento de Filosofía, Universidad de Buenos Aires; Investigadora Principal CONICET, Directora Instituto Investigaciones Filosóficas SADAF-CONICET. dperez@filo.uba.ar Líneas de investigación: segunda persona; expresión; emoción. Publicaciones recientes: Pérez, D. (2018) Languages for the analytical tradition. Philosophical Papers, 47/1:1-21. Pérez, D. (2017) Filosofía, ciencias cognitivas y sentido común: el caso de la perspectiva de segunda persona. Revista de Filosofía Moderna e Contemporanea, 6/1. 
of Modern Philosophy. A proper notion of intersubjectivity, we will argue, is not a simple addition to this dichotomy, but it offers the way to get over the traditional philosophical problems that follow from this modern philosophical paradigm.

Keywords: intersubjectivity, self-knowledge, second person, other minds la dicotomía objetivo/subjetivo propia de la filosofía moderna. Una noción apropiada de intersubjetividad, argumentaremos, no es un simple agregado a esta dicotomía, sino que ofrece una manera de superar los problemas tradicionales que se siguen del paradigma filosófico moderno.

Palabras Clave: intersubjetividad, autoconocimiento, segunda persona, otras mentes

\section{Introduction}

There is a growing interest in the second person perspective. The notion was first proposed around the turn of the 21th century (Gomila 2001, 2002; Gallagher 2001; Scotto 2002; Reddy 2008), and it took a long time for the idea to spread widely both in philosophy of mind and cognitive science. In a nutshell, it claims that social cognition works differently in face-to-face interaction as it works in detached, spectatorial, social situations. However, there are diverse ways to conceive of this perspective and their implications. Some of them view it as a capacity for motor synchronization, or for motor interaction, that does not involve any form of mental attribution. Others stay within a phenomenological framework that emphasizes how the other appears in one's consciousness, without any interest in the actual interaction. Still others downgrade second-personal attributions to a form of subpersonal, low-level process. ${ }^{1}$ In previous writings (Gomila 2001, 2002; Pérez 2013, Pérez $\&$ Gomila 2018), we have argued that the second person perspective has to be understood as a genuine perspective of mental attribution, that is activated in situations in which an agent is actively and directly engaged in real-time interaction with another one. We have also argued that the second person perspective is ontologically and conceptually basic, that it cannot be reduced either to first- or third- personal perspectives, in so far as it draws on information about contingent reciprocity that is only graspable from within this standpoint, and that its attributions lack the opacity of conceptual attributions, but are rather transparent, extensional, and context-dependent.

In this paper, we will address the question of the impact of the recognition of this perspective on the traditional problem of knowing other minds. With this purpose in mind, we will first place the notion of a second-personal perspective of mental attribution within the context of the classical problem of other minds, and discuss the epistemic and ontological implications that follow once the second person perspective is honored. In particular, we will examine how its recognition transforms the traditional problem of other minds, both in its epistemological, ontological and semantical dimensions, and offers a way to go beyond the objective/subjective dichotomy of Modern Philosophy. In the second section, we will provide a basic characterization of the problem of other minds, highlighting the underlying assumptions that gave rise to it. In the third section, we will introduce our characterization of the second person perspective, and we will illustrate it with the case of emotional expression in interaction. In the fourth section, we will elaborate on the consequences that follow from

1 See Gomila \& Pérez 2017 for a discussion about these different ways of conceiving the second person perspective. 
this perspective to the traditional problem of knowing other minds. In the closing section, we will extrapolate some conclusions concerning the question of how to loosen the grip of the basic opposition subjective/objective that characterizes Modern philosophy, and how the notion of intersubjectivity is not an addition to it, but the way to get over the traditional philosophical problems that follow from the Modern philosophical paradigm.

\section{The problem of other minds}

Physical objects can only be known from a third person perspective. This is the perspective of objectivity, the way we grasp how things are. This objective standpoint is committed to acknowledge the possibility of multiple different particular points of view from which to perceive how the same thing stands, the possibility of being mistaken or in disagreement when adopting different points of view, and also the possibility of a privileged vantage point in order to approach reality. For the occupants of these points of view, though, the problem of perspectival knowledge is central and constitutive.

Knowing subjects, though, is quite different. They can be known, prima facie, not only from a third person perspective but also from a first-personal one. In other words, subjects can also know themselves «from the inside», so to say. As a matter of fact, this feature is part of what being a subject amounts to. A simple example may help clarify this dual way to approach the knowledge of subjects: a diabetic person may read their glucose level by means of a glucometer but also experiences the sensation of being about to faint, something that happens when the glucose level drops below a certain value. While the first form of access to her state is accessible to anybody, the second is accessible only to herself. For subjects, then, at least these two perspectives, these two ways of accessing their states, have been traditionally distinguished: the third person/objective vs. the first person/subjective perspectives. And there is a striking asymmetry between them: while the former can be adopted by any subject towards any subject, because it is the perspective of objectivity, the perspective of the third person as in the case of physical objects; the latter is available only for oneself, from the first person point of view. Subjective knowledge is necessarily Self-knowledge.

The above distinction is based on an epistemic contrast: the way subjects can know and be known. Since Descartes, the first person perspective was thought of as epistemically privileged. The traditional marks of the first person perspective were directness and certainty (later on downgraded to incorregibility). ${ }^{2}$ Both features are related: my self-knowledge is guaranteed by the fact that it is direct, immediate, non-inferential. If I am in pain, it follows that I know I am in pain. The third person perspective, on the other hand, is inferential, indirect, mediated, even when, as in the example, it is adopted by a subject toward herself. The third person perspective can only provide access to objective data -such as movements, bodily responses, physiological recordings, etc.-, from which to infer the state somebody is in, or which process she is undergoing, or which sensation she is experiencing. Therefore, it is fallible, and this epistemic weakness opens up the way for skepticism about whether it can provide knowledge.

2 See Alston 1971 for an exhaustive presentation of a variety of ideas related to the epistemic privilege of first person knowledge. 
This epistemic divide was also connected to the ontology of subjects developed in detail in Modern Philosophy. The alleged first-person privileged access was supposed to be grounded in the very nature of subjects, understood as non-material, but thinking, entities. Self-consciousness was singled out as the essence of subjects. But this very asymmetry implied a skeptical challenge to the possibility of grasping from the third person perspective the same sort of states and process that the first person one grasps. In other words, it remains to be explained whether, and how, we can know what somebody feels or thinks, from the third-personal standpoint, given that it can never get to «the real thing», the spiritual Self whose activity is only self-consciously accessible. Mental states are the specific kind of states that the Self can only know "form the inside". Therefore, it is not obvious that there can be an objective, third-personal, standpoint, for knowing other Selves' mental states, if each subject can only access their own mental states. Introspection may work for one's own states, but it is not a reliably guide in order to know other subjects feelings or experiences.

This question was not just rhetorical or speculative. At the turn of the $19^{\text {th }}$ century it became central in the debates about the scientific character of the new disciplines that were emerging, from the social sciences (anthropology, sociology, psychology), to the humanities. How can we ground a science of society if we can only know subjects from an objective, third-personal, standpoint? Against those that pretended to ground these new disciplines on introspection, on the internal lives of subjects, these sciences only made advances when they found their way towards a definition of social facts that made possible for them to be studied independently of subjective attitudes. "Psychologism" in Social Science was set aside, as much as in Logic.

But in the $20^{\text {th }}$ century, the problem of other minds also acquired a semantic dimension, as a result of the linguistic turn that took place in Philosophy. It become part of the problem of other minds to account for the meaning of mental terms (and the corresponding mental concepts they express), and it was put into question the idea that the meaning of mental terms were the same when they are used in first-personal attributions as when they are used in third-personal ones, because each use has a different kind of evidential grounding. Thus, it becomes a pressing question whether the term "pain", for instance, can be said to have the same meaning in a third-personal attribution like "He is in pain" vs. a first-personal one like "I am in pain", given that the meaning of the term "pain" is connected to the mastering of the conditions in which it can be meaningfully used. If both the subjectivethe objective perspectives are so epistemically different, it is not obvious that these mental predicates may have the same meaning in both attributions. To put it in another words, the semantic problem of other minds arises because it seems that each perspective constraints what can be referred to in the first place. To put it in a nutshell, it is the problem of whether each perspective constraints what can be known, and whether there is any guarantee that both perspectives give access to the same mental state. Therefore, the question is whether there is any guarantee that both perspectives give access to the same mental state, and correspondingly, whether both uses (in first vs. in third person attributions) of the mental term have the same reference. On the one hand, if our mental terms are grounded in our self-conscious experiences, then we cannot be sure that other people enjoy the same sort of experiences, given that we cannot experience theirs by definition, because such experiences are subjective, or belong to a subject. On the other hand, if mental terms are grounded only 
in public behavior, then we cannot be sure that what we refer to when using, for ex. the word "pain", has anything to do at all with what we are picking up "from the inside" by introspection (Wittgenstein 1953).

This problem is even more pressing when an explicitly epistemic theory of meaning is assumed -when it is assumed that mastering the meaning of a term, and the content of the corresponding concept, involves mastering the (epistemic) criteria that license its application. Notice that this is weaker than the verificationist theory of meaning defended by logical positivists, according to which the meaning of a term is not anymore something like a definition (the old Aristotelian "essence") but it equals the procedures required to make sure the reference is of the right kind. An epistemic theory of meaning just requires that a competent speaker is one that knows the conditions of application of the terms -otherwise, her utterances would just be parrot-like. Understood this way, the problem of other minds is not just whether the third person perspective may provide access to the same mental states than the first person one, but whether it makes sense to raise the possibility of disagreement between both perspectives in the first place, rather than talking about different things, given that the criteria involved in the application of mental terms seem to be clearly different depending upon the perspective involved, given the epistemic asymmetry between the two (Malcolm 1962). Therefore, the meaning of mental terms, and how mental concepts are grasped, also becomes part of the problem of other minds.

\section{The analogy theory of mental attribution and its theoretical alternative}

This historical view of the problem of other minds helps to realize the limitations of the traditional way to deal with this problem. One traditional answer to the problem of other minds was the analogy theory (Mill 1865). The analogy theory puts the first person perspective in the foreground and derives the possibility of third-personal attributions from the privileged access one has to one's own beliefs, emotions and sensations. In this vein, I can attribute mental states to another because I assume that the other is analogous to me. In order to know other people's minds I must first infer what I would experience in the current situation of the other person, and then to project the inferred state to her.

This precedence of the first person perspective has been under attack from multiple fronts during the twentieth century. On the one hand, the methodological debate that took place at that time about the methods of social and human sciences showed the limitations and arbitrariness of such a view, given that each interpreter may come with a different attribution, without a way to test them. Second, analogical inference came under philosophical disrepute for its lack of grounding: there is no logical possibility to check whether ascriptions by analogy to others are right or wrong, or merely stipulative, given that in principle there is no other way to access the supposed mental states of others than from one's one standpoint (Ryle 1949). Another strategy to expose the lack of support of this kind of analogical inference is to show that it is an inductive inference supported by only one case, which is clearly insufficient (Avramides 2001). Third, the epistemic privileges of the first person have also been put into question. Certainty was rejected as a mark of self-attributions, with plenty of examples of confabulatory self-ascriptions (Hirstein, 2006; 2009). Even the incorrigibility version of the thesis has been criticized due to the high frequency of cases 
of self-deception and irrationality (Gomila 2007) --and despite efforts to make first-person authority a constitutive part of the very notion of a subject (Wright, 1998; Bilgrami 2006).

Despite its discredit, the analogy theory was revived within Cognitive Science in the studies on mental attribution, under a new name: "Simulation theory" (Goldman 1989, 1993, 2006; Gordon 1986, Heal 1986). The analogical projection is now substituted by a simulation process, which takes place in oneself and its result is finally projected onto the other. In general, simulationists have been unaware of the traditional problems for the analogy theory, such as the basic ambiguity that infects the very project of putting oneself in another's shoes, because I can do it as myself, or I can do it trying to imagine as much as possible that I am the other person (Gomila 2002). For example, I can imagine what Hitler might think if I were him but trying to imagine what I, as I am, might think were I to live in Hitler's epoch; or, alternatively, I can imagine, even if it makes me shudder, what I would think if I were in Hitler's situation being him. Simulation theory found a strong ally in the dominant interpretation of the mirror neuron system in terms of simulation (Gallese 2005; Rizzolatti \& Sinigaglia 2010). But this interpretation of neuronal processes is not the only one: they can also be interpreted in terms of second-personal, interactive processing (Gallagher 2008; Schillbach 2010), as Gallese himself has come to defend later on (Gallese 2016).

On the other hand, a powerful alternative approach developed in different forms, according to which third-personal attributions are basic. Wittgenstein's argument against a private language can be seen from this standpoint: mental terms get their meaning as long as they are understood as part of a public language, being constrained by the social practices (implicit rules, conventions and «forms of life») that sustain the uses of these terms. Behavior becomes primary, and Cartesian dualism becomes unintelligible, from this point of view. Functionalism (Lewis 1966, 1970), in its turn, assimilated mental concepts to the theoretical terms of science, which are grounded into patterns of sensory inputs and overt behavior. This trend culminates in positions that conceive self-attributions as third-personal ones (Ryle 1949; Dennett 1987; Gopnik 1993; Carruthers 2011), in spite of the epistemic differences in the way they are empirically supported. Only expressivism remains an alternative in order to honor the asymmetry between first and third person attributions while avoiding the idea of a special first-person epistemic «access» to our internal states (Bar-On 2004; Finkelstein 2008); or, alternatively, a broader «grammatical» understanding of the asymmetry (Pérez 2014). Normative theories of agency (such as Rational Decision Theory or Game Theory) also provide theoretical standpoints for attribution that do not relay on self-attribution. In this later case, a further problem of normativity/rationality emerges, given that it has become common knowledge that these normative theories fail as descriptive theories of human behavior (Kahnemann 2011).

\section{The second person perspective}

According to the "second-person perspective", mental attributions guide human interaction through an embodied practice of "emotional, sensory-motor, perceptual and nonconceptual" reciprocal responses (Gallagher 2001, p. 85). Gomila $(2001,2002)$ argued that the second person perspective is a genuine perspective of mental attribution, where transparent mental states are attributed to each other in the dynamical unfolding of a face-to face interaction. In 
his view when two people engage in direct -face to face- interactions the expressive aspects of the body are seen as significant (not interpreted as such) hence, the body becomes a necessary condition for engaging in this type of interaction. This intersubjective encounters are reciprocal: each participant attributes a psychological state to the other and in that very same act there is a modification of their own mental contents, in real time, as reciprocally contingent information is expressed and perceived (Butterfill 2012). These interactions typically also involve an emotional engagement: the two subjects must be able to have emotions in order to be involved in a relationship of this type, and by default, the interaction is rewarding: we are social beings which find interaction fulfilling. It is not part of this view that the emotion in each subject should be the same as in the other; the important thing is to have an emotional reaction -someone else is suffering, I feel compassion, someone has an unrequited love, I suffer too, etc. In order to make this basic kind of mental attributions no "meta" activity is needed, instead a mental state is caused by the state of the other person and so on; and no language is required in order for these interactions to work. The paradigmatic example of this kind of mental attribution is the one made in the intersubjective interaction between a baby (in her first year of life) and her caregiver.

According to the second person perspective, these dynamical reciprocal and emotionally engaged interactions are the basic situations in which people understand each other's minds -both conceptually, ontogenetically and phylogenetically. Second-personal attributions are our way to access the mental world, through simpler attitudes and simpler contents. Propositional attitude attribution is a late achievement in development. We argued in previous works (Pérez 2013; Pérez \& Gomila 2018) that the mental concepts we need in order to make propositional attributions are language dependent (i.e. they develop as language abilities are acquired) and hence that in the course of ontogenetic development humans beings acquire more complex psychological concepts allowing them to make more complex mental attributions. Moreover, due to the fact that human beings learn psychological concepts while engaged in intersubjective settings, the possession conditions of these concepts include the abilities to apply them both to herself and to others appropriately. Thus, unlike Goldman's theory (Goldman 1993) that contends that psychological self-attributions are prior to attributions to others; and unlike Ryle and the theory -- theorists (paradigmatically Gopnik 1993), who claim that attribution to others is previous, we hold that the abilities required to make both hetero- and self-attribution are among the basic possession conditions of every mental concept (Strawson 1959).

Thus, for illustration, let's take the case of our natural experience of emotional interaction with another person. What we see is that she is smiling, or happy, or sad. Our perceptual experience is not of movements, body parts, and configurations, but of meaningful states -just as our oral experience is of verbal meanings, not of sounds to be interpreted. As this example also shows, of course this personal experience is mediated by knowledge-based subpersonal processes, which may require time to be acquired. But the claim is that at the personal level, our experience is of meaningful expressive, or intentional states, not of data from which to infer those states.

Of course, emotional expression can be faked, and it is possible both to adopt a first- or third- person perspective on emotion. I can wonder whether the sadness I see is authentic, and I may come to the conclusion that it is or that it is faked. This third-personal standpoint is clearly inferential. And I can also wonder what it is that I am feeling at some point, thereby 
adopting the first personal one. The main thesis supported by the second person perspective is not to deny that these other perspectives are possible, or legitimate. It is just to clarify that the second person perspective is genuinely distinct, and irreducible to any of the other two. Even more: these two other perspectives develop once we have got into the mental domain through our second-personal, intersubjective, interactions with others.

Moreover, the second person perspective also highlights the fact that my grasp of another's mental state, through our perception of the perceptual cues that express it, mediates my emotional reaction to such mental state. This reaction is not reflective or strategic -even though it may be if I'm in third-personal mood. My perception elicits a corresponding expression in me, which gives rise to a dynamic interaction: an exchange of expressions that takes place in a temporal pattern. I may react with laugh to your laugh, or with anger, if I see your laugh as your response to my fall, for instance. To put it another way: the fact that I respond emotionally to the emotional expression of another reveals the implicit mental attribution that has been done. My reactions are sensitive to these implicit, context-dependent, attributions. As we already said, these attributions are not conceptually articulated, they come short of grasping how the other conceives of the situation; they are extensional and transparent, as they are spontaneous and practical.

Of course, there are no epistemic guarantees that such attributions are foolproof. We are not proposing that we have a sort of privileged access to the minds of others. The point of the second person perspective is rather that, in the interaction, perceptual cues that are contingent upon the reciprocal interaction become available to the interacting subjects, in a way that are not so available to spectators (Butterfill 2012).

That is the reason why engagement matters. This cycle of interaction entails a second epistemically relevant element: I can infer my own mental state as a consequence of realizing another's emotional response to my previous emotional expression. In this way, the second person perspective contributes to understanding the nature of the first person one, not in terms of privileged access to an inner world of subjective experiences, but in terms of a conceptual capacity of making sense of my own experiences. I may become aware of my resentment when I notice your irritation at my efforts to contain it. And vice-versa: I may better understand what you are expressing when I notice how your expression is contingent upon my own expression. To insist: of course, it is also possible to do all of this reflectively, but our contention is that it usually takes place spontaneously, non-inferentially, through this process of intersubjective engagement.

A consequence of this proposal is that our mental attributions are context- and agentrelative. The more we interact with somebody, the better our attributions. Mental understanding does not begin as a universal, or theoretical ability, but it is grounded in canonical situations of familiar interactions. Our past history of interaction, of previous mutual adjustments, has a cumulative effect, which allows us to better anticipate each other mental states in context. Besides, these reactions usually become normatively regulated in some contexts. As in the laugh at the fall example, the interaction may modify the spontaneous response -just as we become able to dissimulate our gut feelings in some social contexts, because we realize they are disapproved. Fiction also reveals that the second person is active even in contexts where interaction is not possible (Gomila 2013). 
Anyway, it is clear that such interactive patterns cannot be explained either from the third or from the first person. They are fast and spontaneous, directly understood at the personal level, and they are not the outcome of an inferential process. We do not treat each other as Sherlock Holmes takes the clues to solve a mystery. When I laugh at somebody's fall, I do not simulate what she might be feeling and project this outcome onto her. In intersubjective interaction, we just manage to make sense of each other in mental terms right away.

\section{Consequences of acknowledging the second person perspective}

In this section, we will argue that once the second person perspective of mental attribution is acknowledged, the traditional problem of other minds dissolves. The second person point of view is not just another perspective of mental attribution that needs to be taken into account, but it also entails the revision of the traditional way to raise the problem of other minds.

To being with, this new perspective calls into question some of the basic assumptions that give rise to the problem of other minds in the first place. Thus, it involves the rejection of the assumption that self-attributions are immediate and direct and hetero-attributions are inferential. As we have shown, the attributions that mediate our intersubjective interactions are also direct and immediate - which is not to be confused as not being subpersonally mediated, as already argued (but probably first person ones are also subpersonally mediated). In addition, directness and immediacy do not grant certainty: one can be misled both in Self-attributions as well as in hetero-attributions. This is not to say that there is no epistemic asymmetry between the first and the second person (or the third). As we have explained, the second person perspective relies on perceptual cues that become available through the interaction, as reciprocal contingencies. The first person perspective does not require any perception. However, from the fact that the information which is relevant for the Selfattribution is different than the one needed for third- and second-personal attributions comes short to sustain the traditional claim of a privileged status for Self-attributions. We have already mentioned that it is not transparent, not even incorrigible. Current research on consciousness reveal that interoception works analogously to exteroception (Cameron 2001).

More importantly, the vindication of a second-person perspective amounts to calling into question the «monadic» character of the Modern subject, according to which each subject is independent of any other subject. The second person perspective rather involves a view of subjects according to which we are constituted by our interactions, by the interdependencies that we establish with one another, before we begin to be able to make propositional attributions to others and to ourselves. Our primary understanding of the mental takes place in our pre-conceptual dispositions to attach to others, to be sensitive to their expressions, and particularly those that are contingent upon our own ones. Interaction with others is a requisite to become a subject.

Another important way in which the second person perspective implies a transformation of the traditional problem of other minds is that from this perspective knowledge of others is grounded in the interaction and engagement with them; it is not grounded in the adoption of a theoretical disinterested perspective, seeking for the explanation or prediction of their behavior. Attribution takes place implicitly as a way to negotiate our interactions with each 
other. It is a form of practical knowledge. The basic assumption is that the second person perspective is constitutively embodied. It calls into question the basic assumption of modern philosophy that a subject is a disembodied entity contingently placed within a body through which it can be ascertained from the outside, but which is useless from the inside.

It does not imply, though, that first and third person perspectives are not genuine, useful or valid. Of course they are. The take home message is that they are interdependent capacities, which develop as we master the practices of social interaction.

\section{Conclusion}

As we have seen the second person perspective on mental attribution offers a new way to approach the traditional problem of other minds, claiming that intersubjectivity is the basic phenomenon on which our understanding of minds (our own as well as the other's) is based. The Modern opposition between two perspectives -subjective vs. objective- is overcome by this new basic starting point: intersubjectivity.

Thomas Nagel $(1979,1986)$ famously claimed that philosophical problems are to be understood as growing from an opposition between two kind of perspectives or standpoints, from which alternative and opposite answers to them can be given: the subjective or first personal or internal standpoint vs. the objective or third personal or external one. The MindBody Problem is one of them, dependent upon the distinction between the epistemic access we have to ourselves vs. the way in which we access to other's people minds, as we explained above. And, as we suggested above, the second person perspective rejects the idea of a disembodied mind that is causally connected to a purely physical body, dissolving at the same time not only the problem of other minds but also the classical setting for the mind-body problem.

But there are other problems that -according to Nagel- also depend upon the subjective/ objective distinction, and that the second person perspective has the potential to overcome. For example, in the traditional problem of free will against determinism, what is at stake is the opposition between our internal intuition according to which we are free agents, against the external or objective point of view according to which we are biological (human) beings whose actions are determined by natural laws. Strawson's famous "Freedom and Resentment" overcome this traditional philosophical problem with the notion of "reactive attitudes" that could be considered as an antecedent of our second persons interactions. Another example: consequentialism claims that moral reasons should be objective or third personal: no matter what the characteristics of the agent or the situation are, the moral action would be the one that maximizes welfare (or pleasure) to the majority of people. On the other hand, deontologism is sensitive to the agent standpoint and situation: all actions should be evaluated as right or wrong from the agent perspective. But maybe the place to look for moral reasons is not in the realm of objective/universal laws, or in each agent's perspective, but in intersubjective settings where someone's actions affect a particular other's life. Maybe second-personal reasons (Darwall 2006) are at the bottom of every ethical question.

As we can see, many traditional problems at the core of philosophy can be stake out from a second person perspective. In this paper we developed one of them: the problem of other minds. The detailed presentation of these other issues will be the subject matter of other contributions. 


\section{References}

Alston, W. (1971) "Varieties of privileged access". American Philosophical Quarterly 8(3): 223-41.

Avramides, A. (2001) Other Minds. London: Routledge.

Bar-On, D. (2004) Speaking my mind. Oxford: Oxford University Press.

Bilgrami, A. (2006) Self-Knowledge and resentment. Cambridge: Harvard University Press.

Butterfill, S. (2012) "Interacting mindsreaders". Philosophical Studies, 165: 841-863.

Cameron, O. G. (2001) Visceral sensory neuroscience: Interoception. New York, NY: Oxford University Press.

Carruthers, P. (2011) The Opacity of the Mind. Oxford: Oxford University Press.

Davidson, D. (1992) “The second person”. In P. French (ed.) Midwest Studies in Philosophy, vol. XVII: 255-267.

Davidson, D (2001) Subjective, Intersubjective, Objective. Oxford: Oxford University Press.

Darwall, S. (2006) The Second Person Standpoint. Cambridge: Harvard University Press.

Dennett, D. (1987) The Intentional Stance. Cambridge: MIT Press.

Finkelstein, D. H. (2008): Expression and the Inner. Cambridge: Harvard University Press.

Gallagher, S. (2001: "The practice of the mind: theory, simulation, or primary interaction", Journal of Consciousness Studies 8, pp. 83-108.

Gallagher, S. (2008) “Embodied social cognition”. In P. Calvo \& A. Gomila 2008: Handbook of Cognitive Science: an embodied approach. London: Elsevier, pp. 441-450.

Gallese V. 2005 'Being like me': self-other identity, mirror neurons and empathy. In S Hurley \& N Chater (eds.) Perspectives on imitation: from cognitive neuroscience to social science, vol. 1. Cambridge, MA: MIT Press, pp. $101-118$.

Gallese, V. (2016) Bodily selves in relation: embodied simulation as second-person perspective on intersubjectivity. Philosophical Transactions of the Royal Society B, 369: 20130177.

Goldman, A. (1992) "In defense of the simulation theory". Mind and Language, 7(2):104-119.

Goldman, A. (1993) "The Psychology of Folk Psychology". Behavioral and Brain Sciences 16

Goldman, A. (2006) The Simulating Mind. The philosophy, psychology and neuroscience of mindreading. Oxford: Oxford University Press.

Goldman, A. y Gallese, V. (1998) "Mirror Neurons and the Simulation Theory of MindReading". Trends in Cognitive Sciences 2(12): 493-501.

Gomila, A. (2001) "La perspectiva de segunda persona: mecanismos mentales de la intersubjetividad". Contrastes, vol. suplementario $\mathrm{n}^{\circ}$ 6: monográfico sobre Filosofía actual de la mente, P. Martínez-Freire, ed., pp. 65-86.

Gomila, A. (2002) "La perspectiva de segunda persona de la atribución mental". Azafea, 1: $123-138$.

Gomila, A. (2007) "El retorno de la represión”. Teorema, 26/3: 97-112.

Gomila, A. (2013) "Las emociones en el teatro: ¿por qué nos involucramos emocionalmente con una representación?" En G. Soria Tomás (ed.) La representación de las pasiones: perspectivas artísticas, filosóficas y científicas. Madrid: Dykinson, pp. 57-78.

Gomila, A. \& Pérez, D. (2017) "Lo que la segunda persona no es”. En Pérez, D. and Lawler, D. (eds.) Las emociones y la segunda persona. Buenos Aires: SADAF, pp. 275-297. 
Gopnik, A. (1993) "How we know our minds: The illusion of first-person knowledge of intentionality". Behavioral and Brain Sciences, 16: 1-15.

Gordon, R. (1986) "Folk Psychology as simulation". Mind and Language, 1(2): 158-171.

Heal, J. (1986/1995) "Replication and Functionalism". Reprinted in M. Davies and T. Stone (eds.) (1995) Folk Psychology. Oxford: Blackwell.

Hirstein, W. (2006): Brain fiction: self-deception and the riddle of confabulation. Cambridge: MIT Press.

Hirstein, W. (2009): Confabulation: views from neuroscience, psiquiatry, psychology and philosophy. Oxford: Oxford University Press.

Kahneman, D. (2011) Thinking, fast and slow. New York: Farrar, Strauss \& Giroux.

Lewis, D. (1966) “An Argument for the Identity Theory”. Journal of Philosophy 63: 17-25.

Lewis, D. (1970) "How to define theoretical terms". The Journal of Philosophy 67(13): 427-446.

Malcolm, N. (1962) "Knowledge of Other Minds". In V.C. Chappell (ed.) The Philosophy of Mind, Englewood Cliffs: Prentice-Hall.

Mill, J.S. (1865) An Examination of Sir William Hamilton's Philosophy. London: Longmans.

Nagel, T. (1979) "Subjective and Objective". In Mortal Questions New York: Cambridge University Press.

Nagel, T. (1986) The view from nowhere. New York: Oxford University Press.

Pérez, D. (2013) Sentir, desear, creer. Una aproximación filosófica a los conceptos psicológicos. Buenos Aires: Prometeo.

Pérez, D. (2014) "Asimetría y conceptos psicológicos”. Páginas de Filosofía, 18: 5-26.

Pérez D. \& Gomila, A. (2018) "La atribución mental y la segunda persona”. En Balmaceda, T. \& Pedace, K. (comps.) Temas de filosofía de la mente: Atribución psicológica. Buenos Aires: SADAF, pp. 69-98.

Reddy, V. (2008) How infants know minds. Harvard, Mass.: Harvard University Press.

Reddy, V. \& Morris, P. (2004) "Participants don't need theories. Knowing minds in engagement". Theory and Psychology, 14: 647-665.

Rizzolatti, G. \& Sinigaglia, C. (2010) "The functional role of the parieto-frontal mirror circuit: interpretations and misinterpretations", Nature Reviews Neuroscience, 11: 264-274

Ryle, G. (1949) The Concept of Mind. London: Hutchinson.

Scheler, M. (1922) Wessen und formen der sympathie. [Esencia y formas de la simpatía. Buenos Aires, Losada 1943, traducción de José Gaos].

Schillbach, L. (2010) "A second-personal approach to other minds". Nature Reviews Neuroscience, 11: 449.

Scotto, C. (2002) "Interacción y atribución mental: la perspectiva de la segunda persona", Análisis Filosófico, vol. XXII, no. 2: 135-151.

Strawson, P. (1959) Individuals. An Essay in Descriptive Metaphysics. Londres: Methuen.

Strawson, P. F. (1962) "Freedom and Resentment" In Gary Watson (ed.), Proceedings of the British Academy, Volume 48: 1962. Oup Oxford. pp. 1-25.

Wittgenstein, L. (1953) Philosophical Investigations. Oxford: Blackwell.

Wright, C. (1998): “Self-knowledge: the Wittgensteinian Legacy”, en A. O'Hear, ed.:

Current Issues in Philosophy of Mind (The Royal Institute of Philosophy,

Supplement 43). Cambridge U.P., pp. 101-121. 